\title{
INVESTIGATION OF SHEAR ZONES IN THE ICE SHEET MARGIN, THULE AREA, GREENLAND
}

\author{
By George K. Swinzow \\ (U.S. Army Cold Regions Research and Engineering Laboratory, Hanover, N.H.)
}

\begin{abstract}
The structure of silty ice bands and the formation of their resulting shear moraines are investigated in the light of new evidence provided by two ice tunnels and additional surface investigation in the general Thule area. Previous investigations are examined and discussed; a new interpretation of the phenomena is presented.
\end{abstract}

Résumé. La structure de bandes de glace limoneuse et la formation des moraines de cisaillement qui en résulte sont examinées à la lumière d'une nouvelle preuve fournie par deux tunnels de glace et des observations supplémentaires en surface dans l'ensemble de la région de Thule. Des investigations antérieures sont examinées et discutées. Une nouvelle interprétation du phénomène est donnée.

Zusammenfassung. Die Struktur versandeter Eisschichten und die daraus entstehenden Geschiebemoränen werden im Lichte neuen Beobachtungsmaterials untersucht, das in zwei Eis-Stollen und durch zusätzliche Oberflächenuntersuchungen in der weiteren Umgebung von Thule gewonnen wurde. Frühere Untersuchungen werden uberprüft und diskutiert. Eine neue Deutung der Erscheinung wird vorgelegt.

\section{INTRODUCTION}

THE excavation of two ice tunnels in the margin of the ice sheet at Thule, Greenland, has provided new data on the nature of the rock inclusions which form shear moraines at the surface of the ice sheet. Silt bands, some heavy accumulations of boulders and gravel, and streaks of clayey ice exposed by excavation were available for detailed study during $195^{8-59}$.

It is commonly believed that the rock material in the ice was dragged from the bottom of the glacier along gently curved planes, but the actual nature of the bottom of the glacier is unknown. It may be bedrock in some places, but it also may be patterned ground and permafrost, as in front of the glacier. It may also be a thick band of inclusions. An aerial reconnaissance flight revealed patterned ground extending to the edge of the glacier and apparently underneath it. The bottom of the ice-margin lakes is also composed of patterned ground which disappears beneath the glacier.* Seismic evidence available at the present neither discloses the nature of the reflecting surfaces nor establishes the actual glacier bottom-the surface on which the glacier moves.

Several investigators in the past have based interpretations of the shear moraine phenomenon upon surface examinations and investigations of aerial photographs. Rausch (1958) concluded that the forward motion of the ice is blocked by moraine debris in front of it. Harrison ( 1957) applied a new technique for three-dimensional fabric analysis of sediments and gave a broad interpretation of the significance of the orientation of single particles in ice; he concluded that motion along shear zones may produce reorientations of the material which can remain as evidence of the action of the glacier on the debris. Bishop (1957) has discussed the influence of subglacial topography on the formation of shear moraines.

This paper is an examination of the shear moraine problem in the light of new evidence collected in the general TUTO area during $195^{8-} 59$.

\section{INCLuSIONS IN THE IGE OF THE TUTO TunNELS}

Rock debris in the western margin of the Greenland Ice Sheet has been observed in two ice tunnels (Fig. I). The lower tunnel has an elevation of $1,573 \mathrm{ft}$. (479 m.) above sea-level.

* As seen in a cave formed in the ice by melt water, accessible for about $800 \mathrm{ft}$. (250 m.) into the ice, investigated in 1960 and $196 \mathrm{r}$. 
Silt, sand, and rock are exposed in its walls throughout the entire length. Very few places in the tunnel are free of such inclusions, which form layers several feet thick in many instances.

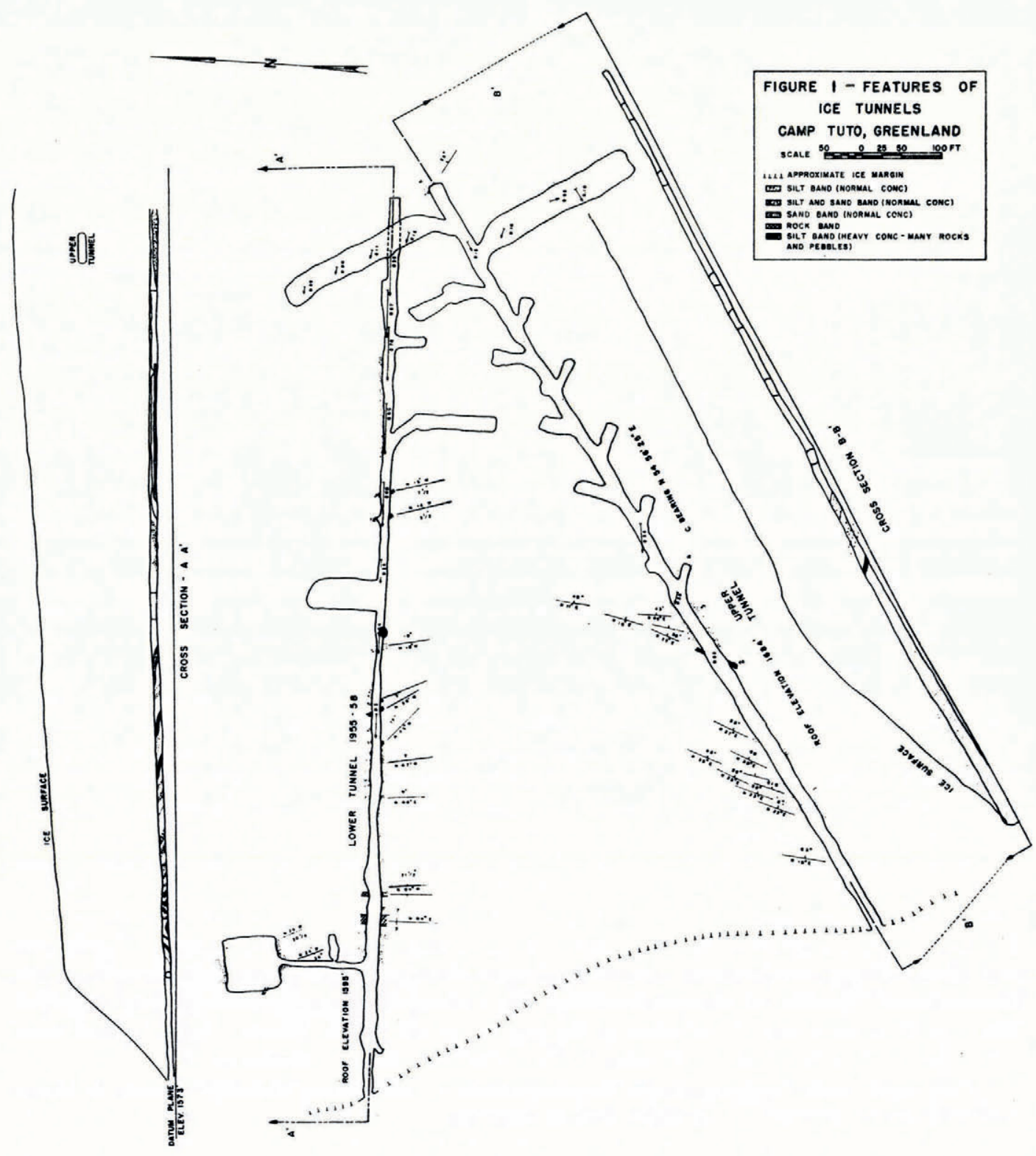

Fig. I. Features of ice tunnels

Dipping generally east-north-east away from the entry at a low angle (o to 17 degrees). The average strike is $45^{\circ}$ west of north. The inclusion bands are characterized by a persistently sharp delineation and an even distribution of the inclusions. Between 200 and $300 \mathrm{ft}$. (6o-90 m.) 


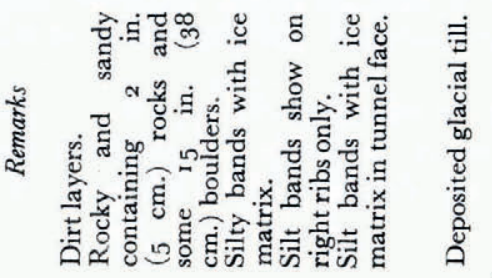

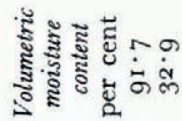

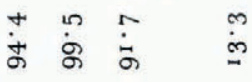

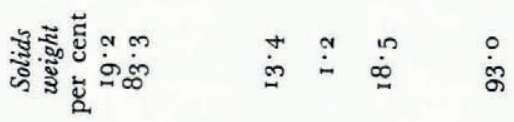

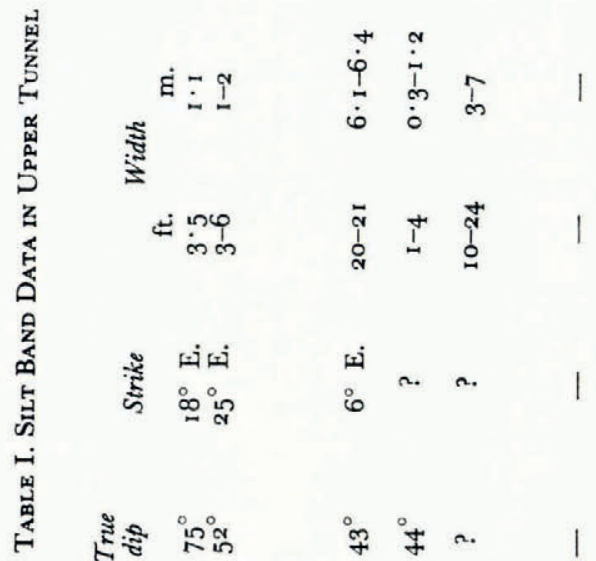

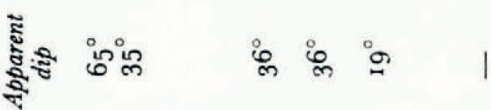

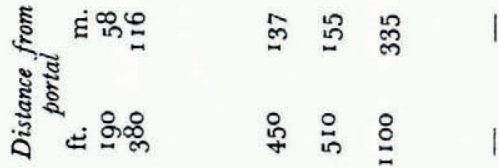

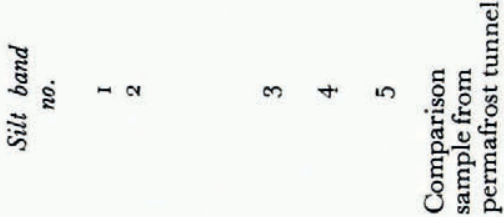


from the portal there is a zone of badly distorted bands, some vertical, and irregular masses of inclusions. The inclusions in the immediate vicinity of the tunnel portal dip toward the portal.

The upper tunnel has an elevation of $1,653 \mathrm{ft}$. (504 m.) and extends $60^{\circ}$ east of north. Unlike the lower tunnel, inclusion bands are present primarily in the first $55^{\circ} \mathrm{ft}$. ( $170 \mathrm{~m}$.). The average strike is $15^{\circ}$ east of north and all show a pronounced dip to the east measuring roughly $5^{\circ}$ degrees.

\section{Composition of the Inclusion Bands}

The material included in the ice varied from clay-size particles of only a few microns to cobble stone of 6 or more inches ( $15 \mathrm{~cm}$.) in diameter. Boulders larger than $6 \mathrm{in}$. ( $15 \mathrm{~cm}$.) were seldom encountered during excavation though they were abundant on the surface. This is attributed to removal by wind and water of the finer fraction resulting in an apparent discrepancy between source and deposit.

Pebbles and boulders imbedded in the ice display three types of surface abrasion: wear by water, wind polishing, and, in two instances, wear by glacial action. The absence of rock with no surface abrasion is remarkable.

The form of the larger particles suggests two types of abrasion in addition to terrestrial physical weathering; well-rounded grains produced by running water are mixed with material subsequently abraded by glacial action. The fine material bears more noticeable traces of frost action than does the coarser material. Fine fragments are angular with only the sharpest protrusions removed by water wear; disintegration along grain boundaries and fractures along cleavage planes indicate that they have been subjected to sharp fluctuations of temperature.

Samples from the most prominent silt bands of the upper tunnel were dried and the volumetric ratio of ice to solids calculated (Table I). Bands with a predominance of fine material displayed in situ a varve-like, fine laminated structure possibly produced by differential flow in the ice. The individual layers of silt in a band were 2 to $12 \mathrm{~mm}$. thick.

The results of moisture content determinations of samples from the lower tunnel are shown in Table II.

Table II. Ice Content of Silt Band in Lower Tunnel

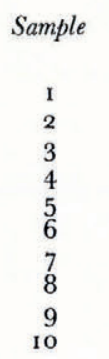

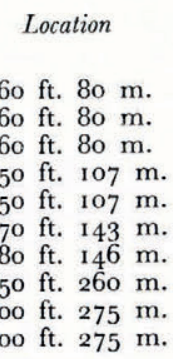

\section{Description}

\section{Fine silt}

Boulders up to 6 in. ( $15 \mathrm{~cm}$.)

Pebbles and gravel

Fine silt, distorted

Banded clay, sand up to $2 \mathrm{~mm}$.

Clayey silt, rocks

Clayey silt, rocks

Clayey, dirty ice

Thin silt band, $\mathrm{I} \cdot 5$ in. $(3.8 \mathrm{~cm}$.)

Fine silt bands 0.5 in. $(1 \cdot 3 \mathrm{~cm}$.) apart

\begin{tabular}{|c|c|}
\hline & conte \\
\hline per cent & by \\
\hline & $\begin{array}{l}55 \\
6 \mathrm{I}\end{array}$ \\
\hline & $5^{\circ}$ \\
\hline & 97 \\
\hline & 90 \\
\hline & $\begin{array}{l}47 \\
51\end{array}$ \\
\hline & 99 \\
\hline & $\begin{array}{l}77 \\
65\end{array}$ \\
\hline
\end{tabular}

The average specific gravity was determined from a series of pycnometric determinations as $2 \cdot 662$ (9 samples).

Similar moisture contents were encountered in the upper tunnel. Bands with a great variation in particle size had a large amount of solids and a high degree of contact between particles, as compared to bands containing equal-sized particles.

Size analysis of samples from five bands in the upper tunnel was made using twelve standard sizes, ranging from 3 in. to 200 mesh. Large original samples were quartered to 
obtain optimum amounts for analysis. The resulting curves are shown in Figure 2. No definite slope trends were established, indicating sources of extreme variety.

Since the finer fraction was considered important for diagnosis, the Vanderwild suspension separation method was used. The method produces separation by circulating a suspension of the material through a series of interconnected vessels where materials of progressively finer sizes settle out, thus facilitating an analysis by size and subsequent microscopic investigation of the various fractions. The convenient hydrometer size analysis was also applied.

U. S. STANDARD SIEVE SIZE
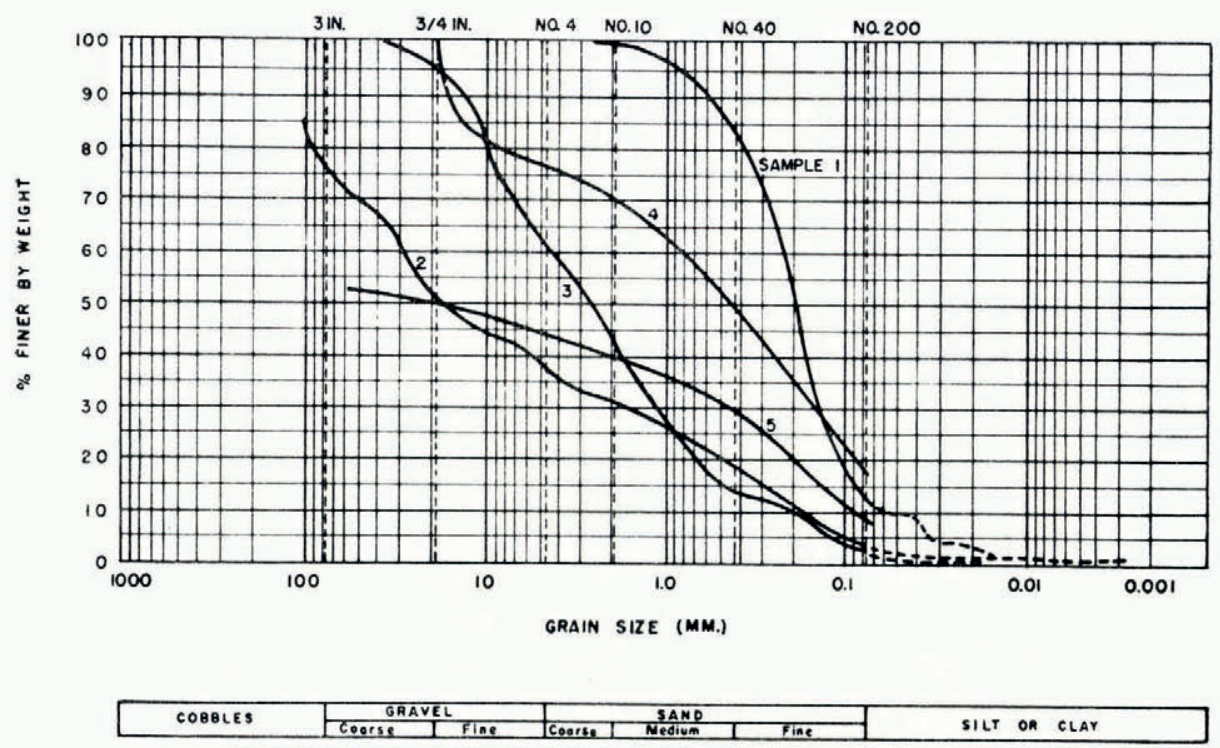

Fig. 2. Mechanical compositions of inclusion bands from the upper tunnel

The two above methods were applied to samples I, 2, and 3, upper tunnel, which had enough fine material to justify such a treatment and make microscopic investigation possible (Fig. 3).

The coarse material consisted of pebbles and boulders of igneous and metamorphic rocks, including granodiorite, quartz-syenite, gabbro, dolerite, gneiss, hornfels, a variety of dark crystalline schists, and graywacke-like metamorphics. Grains smaller than $3 \mathrm{~mm}$. consisted predominantly of a single mineral; only rarely were they composed of several intergrown minerals. Imprints of other minerals, predominantly quartz and feldspar, could be observed on the surfaces of several grains.

Microscopic material obtained by the Vanderwild technique verified the trend mentioned above; every grain consisted of a single mineral. Rounding by wear abruptly disappeared when grains measured $0.1 \mathrm{~mm}$. or less. Grains rounded by solution could be distinguished easily from those worn by transport.

The fresh appearance of angular sharp-edged grains of hard minerals such as quartz, garnet, and others was notable.

Minerals in the fine fraction were altered in two main ways: ( $\mathrm{I}$ ) weathering of feldspars to clay combined with liberation of sericite from the cleavages of disintegrating feldspars, and (2) the formation of limonites and other heavy mineral oxides.

Within the finest fraction of the precipitate, the clay group consisted of kaolinite, illite, 
dickite (?), and other minerals which could not be determined because of limitations in facilities. The mineralogical composition as determined by microscopic investigation is shown in Table III.

The overall impression from comparing upper and lower tunnel minerals is that the latter exhibit a greater degree of surficial weathering, manifested in a higher degree of decomposition of iron-rich minerals and a frequent appearance of limonite staining. Visual observations, together with microscopical work lead to the conclusion that the material of the lower tunnel is derived from upper, more oxidized layers of material than that exposed in the upper tunnel.

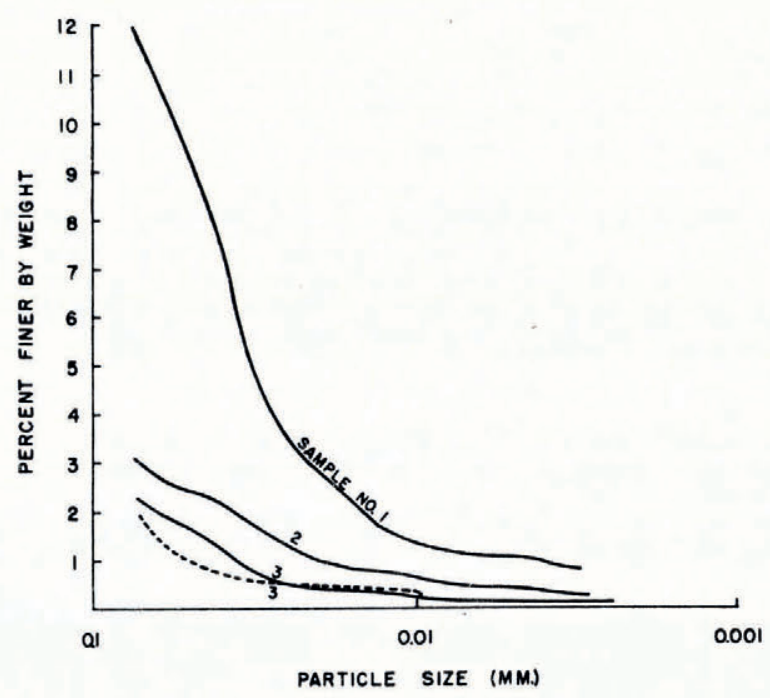

Fig. 3. Mechanical composition of the finer fraction in the upper tunnel

\section{Surface InVEstigations}

Numerous observers have described the outcrops of silt and rock debris at the ice-sheet surface. All of these observers point out the protective rôle of the debris exposed on the top of the ice. The formation of mounds is attributed to retardation of melting by the overlying material. An analogous effect has been produced artificially: the TUTO ramp road has risen 30 to $40 \mathrm{ft}$. ( 9 to $12 \mathrm{~m}$.) above the ice surface over the years, due to the protection from melt given by the road material itself.

The height of a shear moraine ridge is the result of interaction between, (I) liberation of rock debris from the ice and retardation of melting, and (2) the rate of removal by run-off.

One location in the general TUTO area is relatively free of shear moraine development. In this area (from the ramp road and 2.5 miles $(4 \mathrm{~km}$.) south) the outcropping silt bands are thin, spotty, and completely lack coarse material; the small amount of fines is removed as fast as it is produced. The result is a gentle ramp with a complete absence of relief expression. Places of moderate occurrence of material but with a variety of sizes are subject to one-sized sorting: the fines are removed by melt water, resulting in hills paved with boulders. Harrison (1957) reported cases of varved clay deposited at the surface, subjected to immediate outwash, and this observation is confirmed. The location, however, no longer produces this material, but clay was found outcropping 20 to $30 \mathrm{ft}$. (6-9 m.) away, indicating great variability in condition at the edge of the moving ice. Two miles $(3 \mathrm{~km}$.) south of the Harald Moltke Bræ margin the shear surfaces produce such an amount of material that it presently supports 
Table III. Mineralogical Composition of Soil and Rock Inclusions in Tunnels as Determined from Slides Studied Under the Petrographic Microscope

Container no.

I

2

3

4

5

6

7

8
Particle size range

$6 \cdot 670 \mathrm{~mm}$. maximum

$0.045 \mathrm{~mm}$. maximum $0.035 \mathrm{~mm}$. minimum

$0.035 \mathrm{~mm}$. maximum $0.025 \mathrm{~mm}$. minimum

$0.025 \mathrm{~mm}$. maximum $0.015 \mathrm{~mm}$. average

$0.020 \mathrm{~mm}$. maximum $0.012 \mathrm{~mm}$. average

$0.010 \mathrm{~mm}$. maximum

$0.010 \mathrm{~mm}$. maximum

$0.004 \mathrm{~mm}$. maximum

\section{Description}

$40 \%$ quartz $-20 \%$ hornblende $-5 \%$ large, rounded and weathered grains of olivine. Some slightly rounded and weathered feldspar.

$80 \%$ quartz, exhibiting good visible conchoidal fracture, with no round material. Some large grains of green pyroxene amphiboles.

$80 \%$ quartz- $-6 \%$ clays. Grains of olivine more frequent - some grains of hornblende - cleavable pieces of mica some plagioclase feldspars - pyroxenes epidote (questionable).

$70 \%$ quartz-twice as much opaque material as in container no. 3 , and they are rounded-big, soft grains of limonite-grains of microcline, angular and showing cleavage-3 grains of olivine- few flakes of mica.

$70 \%$ feldspars - $20 \%$ quartz - same amount of opaque material as in container no. 4--slightly more limonite grains.

$50 \%$ quartz-20\% dark minerals-10\% claysextremely small per cent of opaque minerals-grains of hornblende, beryl, olivine are present-micas more flaky and elongated-quartz is sharp and angular.

$50 \%$ quartz, sharp, angular conchoidal particles$20 \%$ dark minerals - $10 \%$ clays-limonite and glauconite more predominant-small amount of opaque material-yellow and green staining of limonite is noticeable-no apparent sorting as to composition, even distribution with no rounded particles-grains pyroxene - I grain spinel.

$80 \%$ clays $-20 \%$ sharp, angular feldspars and micadark minerals completely absent-few grains of magnetite-feldspars show different degrees of sericitization.

Note. Where the percentage does not balance, the remainder has to be attributed to unidentified fines or minerals listed only by name.

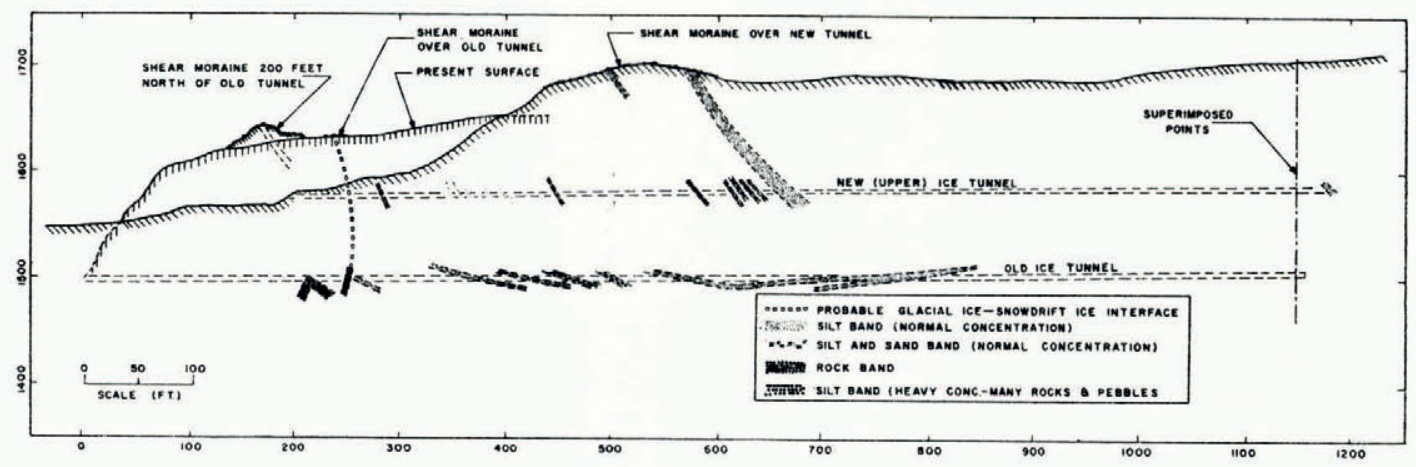

Fig. 4. Composite profile of the two ice tunnels in TUTO

vegetation. The hills are flat, instead of being conical, and have patterned ground at their surface-features common to ordinary permafrost surfaces.

Extensive search, in the area three miles $(5 \mathrm{~km}$.) south of the ramp road revealed a $15 \mathrm{~cm}$. band containing organic material which had accumulated at the surface. It contained peat, plant remnants, willow, etc. In the summer of $196 \mathrm{r}$, most of the material was removed by 
melt water, but the specimens collected in I96o contained the following plants which could be identified:

I. Lichens:

2. Mosses:

3. Higher plants:
Eicopoceium selago

Cladonia pvxocenta

Alletoria jubata (mimiscula?)

Politrichum

Grimmea

Salix poupensis

Salix anana

Papaver radicatum (seeds)

These specimens are typical of the plant life presently flourishing in the Thule area.

No outcrops of organic debris were observed in the tunnels, which is probably a matter of chance, since they have not been observed elsewhere at the surface.

A general view of the outcropping shear moraines shows a tendency toward a broad archshaped pattern, perpendicular to the direction of flow and, in most cases, parallel to the ice edge. The distance from the ice edge varies from a few dozen feet at the ice cliffs to a half mile ( $\mathrm{r} \mathrm{km}$. ) and more.

\section{Ice Motion Measurement}

Measurements of surface ice motion conducted by Griscom (Schytt, 1955), Griffiths (1960) and Rausch (1957) are the only available direct data in the region. Internal velocity distributions through the thickness of ice could presently be obtained only from relative displacement of originally vertically superimposed points in the roof and floor of a tunnel. Since such relative displacements may be regarded as motion differences between two ice levels, they could be presented in the form of limiting angles on a velocity distribution curve. (Table IV summarizes these observations.)

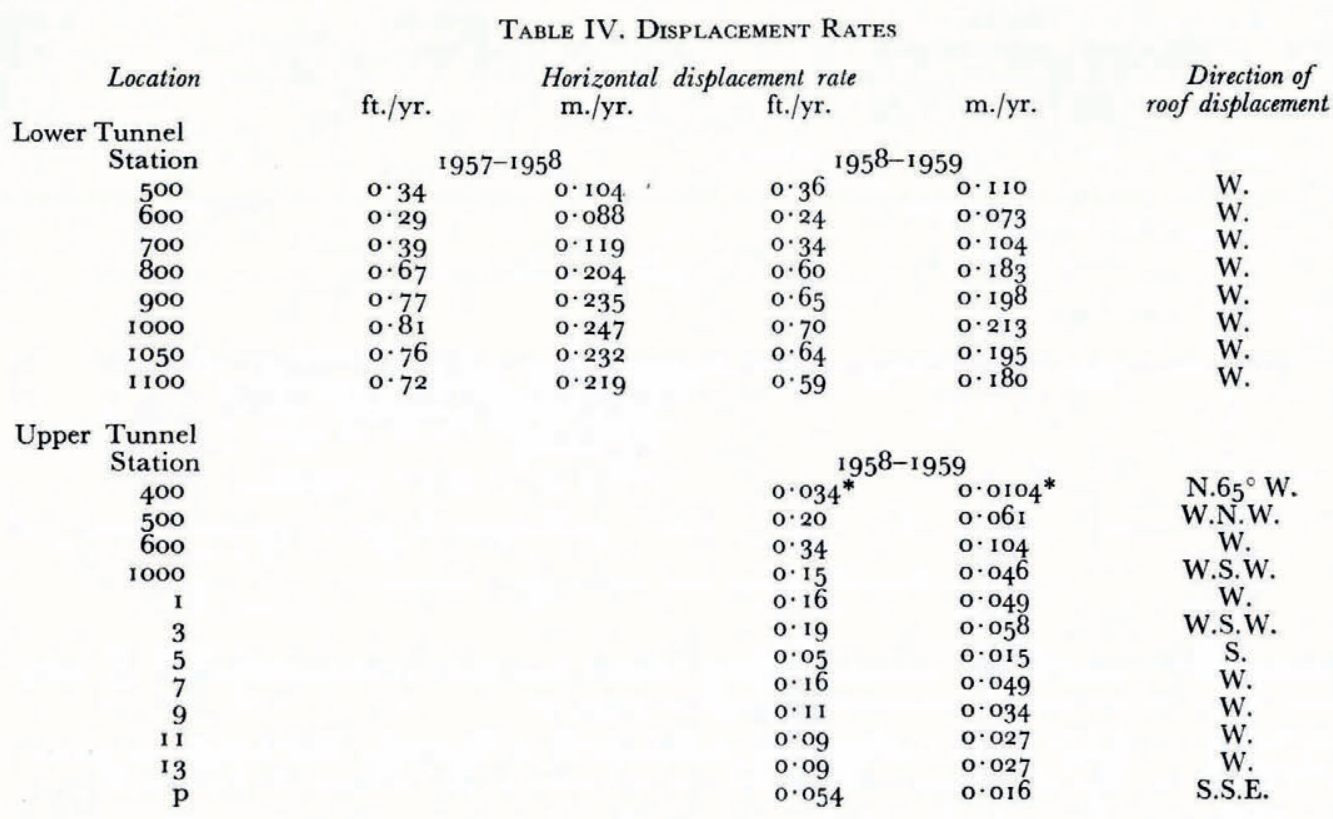

* Determined by dial micrometer indicators. 
The two tunnels have one common point on the map at which a horizontal surface speed of $12.9 \mathrm{ft} . / \mathrm{yr}$. ( $3.9 \mathrm{~m}$./yr.) was estimated (from the above-mentioned observations of Rausch and Griffiths). The vertical velocity distribution curve constructed from these data is presented in Figure 5 where the line A (12.9 ft. $/ \mathrm{yr}$., $3.9 \mathrm{~m}$. $/ \mathrm{yr}$.) is the directly measured velocity at the point of intersection of the two tunnels on the map (see Fig. I). Line B (12.0 ft. $/ \mathrm{yr} ., 3 \cdot 65 \mathrm{~m}$./ yr.) on Figure 5 was obtained indirectly by the construction of an angle on the basis of the measured velocity difference between the roof and the floor of the tunnel. The construction of C ( $9.6 \mathrm{ft} . / \mathrm{yr}$., $2.9 \mathrm{~m}$./yr.) for the lower tunnel is similar. The differences for both tunnels expressed as angles are:

Upper tunnel

Lower tunnel

Difference between lower tunnel and surface
I $\cdot 23$ degrees/yr.

$4 \cdot 5$ I degrees/yr.

I $\cdot 3^{8}$ degrees/yr.

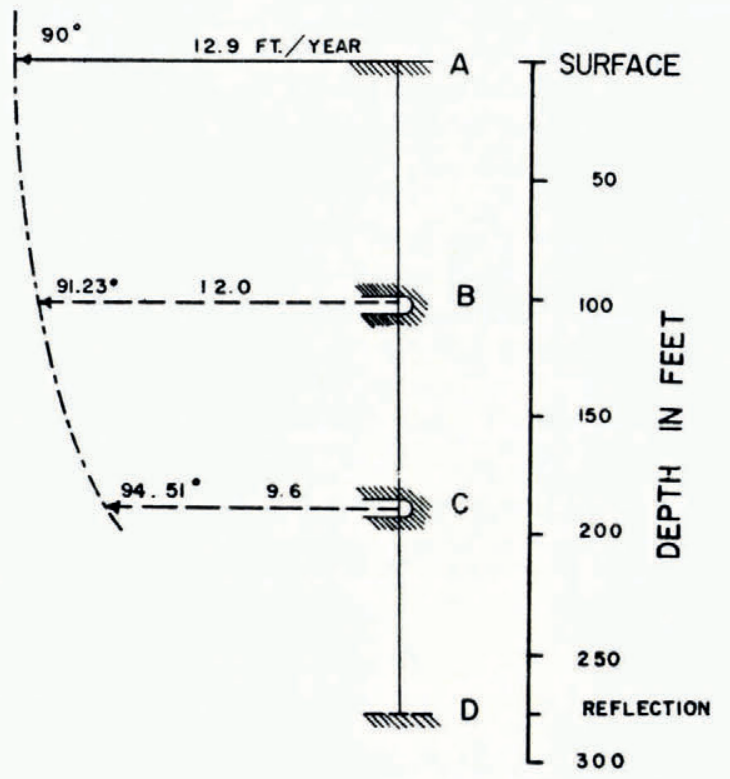

Fig. 5. Vertical velocity distribution for a map point common for the two tunnels

On the basis of these data, one could obtain a graphical solution for the absolute velocities at the level of the two tunnels. Figure 5 presents such a graphical solution of the velocities at the two tunnel levels (points B and $\mathrm{C}$ ).

An attempt to extrapolate downward failed, since the solution of a parabolic equation for depth is possible - on the data given in Figure 5 -three different ways, which in turn give three different results. This may be explained by the possibility of inhomogeneity of the ice. It is also quite possible that between the point $\mathrm{C}$ (Fig. 5) and the bottom, a series of inclusions is present. This would result in a sharp break in the curve. It could be shown that some inclusions may be present between the two tunnels (points B and C in Figure 5).

The mark "Reflection" (Fig. 5) is taken from some seismic data obtained in the vicinity by Dr. Hans Roethlisberger (private communication), and may be that of a stronger silt band.

Mr. John Abel, who directed the excavation of the ice tunnels, installed a series of dial gauges across several silt bands. He found that inclusion bands are surfaces of a great concentration of differential movement. 


\section{Discussion}

The most remarkable difference between the two tunnels is in the dips of inclusion bands (Fig. 4). While the upper tunnel displays inclined bands dipping to the east with a fairly good surface correlation, inclusion bands in the lower tunnel are nearly horizontal throughout the length of the tunnel, with a very small dip, varying slightly. An exception is the exposure near the portal, where badly contorted lenses assume a nearly vertical dip with evidence of redeposition. It could be assumed that this material slumped from the surface of the glacier and was subsequently covered by superimposed ice. Bishop (1957) postulated that the ice between the portal and first rock inclusions of the lower tunnel was formed from wind-blown snow which accumulated in the lee of the ice cliff. Whatever it may be, the material in the first vertical inclusion band is dark, poorly oxidized and mixed, and has no traces of the characteristic stratification of inclusion bands elsewhere.

Material in the silt bands is more oxidized and weathered in the lower tunnel than in the upper tunnel. (This must be due to the effect of glacial scouring, which removes surface material first and deeper seated, less weathered material later.) This difference alone indicates that the glacier could not have been eroding buried landscape for too long or the prolonged abrasion would have removed the surface mantle. In addition, there is no evidence of bedrock being eroded. The presence of plant remnants is an indication that the landscape presently covered by ice was subjected to glacial abrasion only a short time ago. If the assumption (discussed below) that the glacier is presently in a state of retreat is correct, then the retreat began very recently and was preceded by a brief advance.

Consequently, the landscape presently under the ice in the TUTO ramp area still yields periglacial surface materials. All the plants found are characteristic representatives of the present Thule area which is still free of ice. This further indicates that the present state could not be that of a major retreat following a major advance, but only a brief fluctuation produced only by a minor change of mass balance.

The coarse fractions of the inclusion-band material show evidence of subaerial weathering, but the finer material shows definite evidence of boreal weathering at its severe extreme. The absence of water wear on the fine material indicates short periglacial streams moving material in suspension without wear.

An observation in favor of subaerial weathering of the material is that the smaller fraction consists predominantly of monomineralic grains. This is typical of Arctic and, to a lesser extent, desert environment.

The formation of pores for water penetration is the essence of the process of weathering in cold regions, a fact which the textbook concept of weathering does not take into complete account. Pores are formed by temperature change and by the accumulation of stresses on the grain interface because of differences in coefficients of thermal expansion. It is known that an igneous or metamorphic polymineralic rock is completely free of stress at a temperature slightly above that at which the last mineral grain was formed. Rapid changes of temperature in a range considerably below this bring about quick disintegration of the rock and the formation of monomineralic grains. Since ice can form only in comparatively coarse pores, ice wedging plays an insignificant rôle in the formation of fine material under these conditions.

The fine material obtained from the silt bands in the TUTO tunnels is a product of subaerial Arctic weathering. The coarser material is partly worn, rounded, and deposited by streams. The landscape under the ice is conceived to be similar to the present Thule area, a typical periglacial region with a permafrost layer and with stream beds and valley deposits of the usual nature.

Prior to being covered by ice, this region must have been ice-free long enough to develop Arctic bog pockets similar to those presently observed on the plateau north of Thule. Hilty (r959) reports exposing lichen-covered boulders during an excavation of a small ice tunnel in the Red Rock area, but no bedrock was exposed. The material underlying the ice was an 
accumulation of round boulders, apparently flattened at the top. A similar picture was observed by the present writer during a visit to a melt cave in the Thule area (see footnote on p. 215).

These rounded boulders have been observed in many places directly in front of the ice sheet; their most characteristic feature is the presence of glacial striations on the flat top surface. This is considered good evidence of ice sliding over permafrost. Glacial gouging (long striae) is often observed on a large scale in front of the ice in the Thule area.

The presence of these features, together with the microrelief phenomena just described, indicates that permafrost could exist under a moving ice margin. That the marginal area of a slowly retreating ice sheet is immobilized and "fused" to the underlying permafrost, is proven beyond any reasonable doubt; the Arctic Construction and Frost Effect Laboratory in Boston, Massachusetts, conducted a series of drill hole observations of deformation and temperature along the ramp road in TUTO, these observations (available to the writer but not yet published) demonstrate that the ice below a distinct shear zone at the margin deforms only slightly, and above this zone, deformation is of such a magnitude that the drill holes become impassable to the inclinometer used to measure inclination angles.

Observations of drill holes together with ramp-road surveys, established an actual upthrust of the ice in the shear zone. The new ramp road constructed in 1960 displayed approximately $31 \mathrm{~cm}$. of upwards movement between 16 June and 27 August I960.

It appears, in general, that the configuration of the edge of an ice sheet depends upon the balance between ablation and the amount of ice arriving from the accumulation area. If the velocity of the ice increases rapidly from the bottom up and each successive elementary flow layer produces enough ice to balance ablation, a ramp will be formed, since the lowest part of the ice, which is in contact with permafrost, will not melt as readily as the elevated parts. An excess of ice delivered to the margin will steepen the ramp and, depending upon the balance, form an ice cliff.

Either a ramp or a cliff could exist during times of equilibrium. Retreat could be manifested only by a ramp, unless ground temperature at the base of the glacier is positive. An advancing ice sheet will form a small ice cliff unless there is so much sliding at the bottom of the glacier that the ice at the bottom moves as fast as the ice above it.

The described circumstances are distorted by strong marginal streams (which may cut cliffs) and by an excess of drifting snow brought down from the ice sheet. Snow drifts disguise true glacier structure and glacial ablation and could produce a somewhat questionable "advance" if superimposed ice is built up over the years. However, the problem of superimposed ice needs more investigation. Observations of inclusion bands in ice of the same general structure as that previously described as superimposed ice indicate that there is sufficient motion to produce shear.

Figure 6 is a schematic interpretation of two types of silt band deformations observed particularly well in the lower tunnel. Silt bands deform in two distinct ways with respect to the tunnel walls. Bands with predominantly fine material evenly distributed in a suspended state with few contacts between particles deform faster than clean ice, so that in time they protrude from the wall of the tunnel (Fig. 6a); inclusion bands of this kind were found to contain a greater volume of ice than of rock debris. Silt and rock bands where most of the inclusions are in contact with each other deform less readily than the surrounding ice (Fig. 6b). Here, the ice occupies the pores of the material cementing it in a manner similar to frozen ground. In such bands the volumetric ice content was frequently found to be less than $5^{\circ}$ per cent.

The difference in the deformation of clean ice and ice with inclusions could be presented by the following two equations:

$$
\dot{\epsilon}_{\text {ice }}=\left(\frac{S}{B}\right)^{n}
$$




$$
\dot{\epsilon}_{\text {silty ice }}=\left(\frac{S}{B}\right)^{n} \cdot i
$$

where $\dot{\epsilon}$ is the deformation rate, $S$ the pressure applied, $B$ the viscosity characteristic of ice, $n$ a constant describing conditions under which deformation occurs and $i$ is a factor which increases as the ice content decreases, provided that the particles do not come into contact with each other. Equation 2 thus describes silty ice with an ice content high enough to separate the particles from each other. After the particles have come into contact the deformation rate will decrease as the content of solid rock particles increases further. The change between the two types of deformation is discontinuous and the size, shape, and initial concentration of particles play a vital rôle in the process of deformation. Research is needed to investigate the influence of these properties.

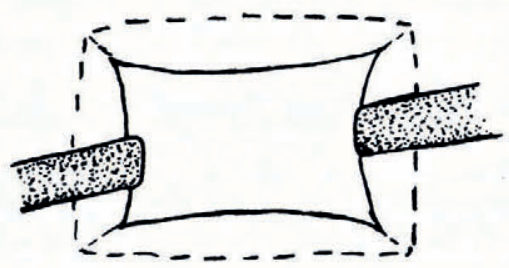

(a)

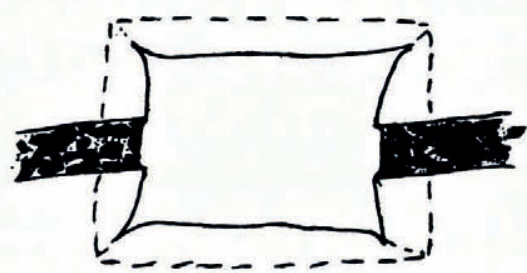

(b)

Fig. 6. Schematic interpretation of two types of inclusion band deformations. Dotted line represents tunnel before deformation; solid line represents tunnel after deformation. In (a) a silt band with suspended particles is a zone of weakness; the band protrudes into the tunnel. In $(b)$ the ice is more plastic than the band which has pebble and rock inclusions, most of which are in contact. The effect in this case is apparently somewhat decreased by the drag of the inward-moving ice

A schematic interpretation of shear moraine formation is shown in Figure 7. Drawing $a$ shows the marginal regions of an ice cap which has just advanced to the position shown and is stabilized. The ice below the silt band moves slower than the ice above or in some cases does not move at all. The band extends an unknown distance to a point where its source is an eroding positive feature of the relief. Three possible situations can evolve from the situation in cross-section $a$ :

I. The glacier will remain at equilibrium for an extended period; the shear moraine at the top of the glacier will increase in thickness, and an increasing amount of material will accumulate at the crest of the shear moraine.

2. The glacier will advance over the morainal deposit which will become a subsequent source for a new shear moraine. The well-rounded, reworked material outcropping in many places in the Thule area indicates that such morainal crests may be in the process of erosion at the present time.

3. The glacier will retreat leaving a morainal ridge especially after a long period of stability. This ridge is seen in the topography of formerly glaciated areas all over the world. 
Cross-section $b$ shows the second stage of a slowly retreating glacier. A second shear moraine is formed. The motion of ice between the inclusion layers may come to a complete standstill. Cross-section $c$ shows the stage of maximum development of shear moraines. The ice is covered by a thick layer of debris which may support vegetation and even ice-wedge polygons. A good example of this stage is the northern-most corner of the tunnel area, I,200 $\mathrm{ft}$. $(350 \mathrm{~m}$.) north-east of the big ice cliffs and one mile $(\mathrm{I} \cdot 6 \mathrm{~km}$.) south of Harald Moltke Bræ along the ice margin. Sections $d$ and $e$ are two final stages. The debris-covered ice is completely separated from the glacier, melting down from the top until the debris layer becomes thick enough to contain the whole active layer.
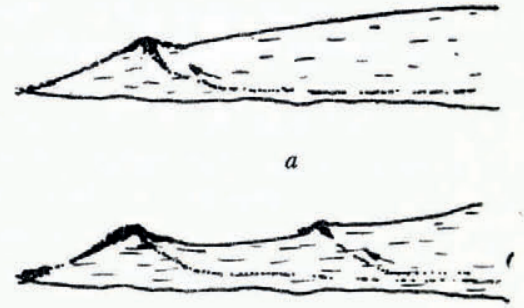

$b$

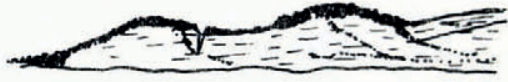

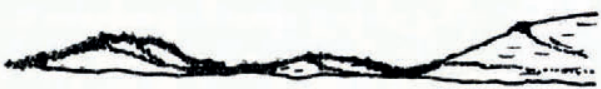

$d$
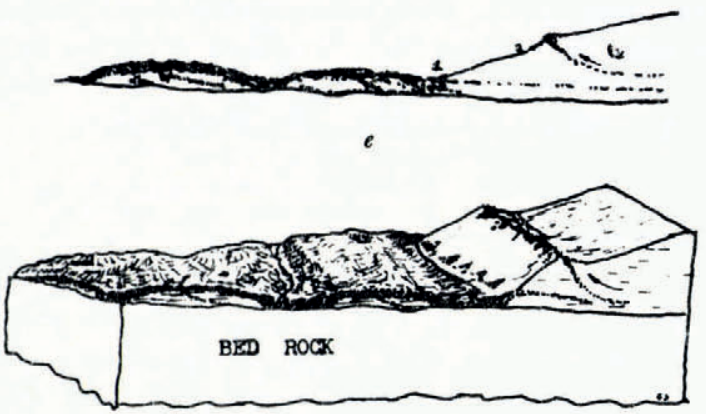

$f$

Fig. 7. Successive stages of shear moraine formation during the retreat of an ice sheet. $f$ is a block diagram corresponding to stage $e$

Further melting of the ice buried can only occur under one of the following conditions:

1. The climate changes and the active layer is depressed below the top of the buried ice.

2. Changes in relief, for example wandering of a debris-laden outwash stream or the undercutting of a small local divide, result in a stream flowing over the buried ice mass. A heat carrier such as water (even cold water) will be destructive to ice just as it is to permafrost.

It is important to emphasize that Figure 7 is simplified and schematic; the rôle of subglacial relief, irregular ice flow, and changes of the amount of debris in shear moraine was not taken into account.

An illustration of the events accompanying advance of a glacier would not necessarily be the opposite of the sequence described. Since the clean ice on top moves faster than that beneath the shear, the inclusion bands will be stretched out and the material in them reworked, the debris will outcrop only during a subsequent retreat, etc.

The formation of shear moraines at the edge of an ice sheet may be explained by the process of ablation. Three possible ideal conditions are considered for interpretation below:

\section{Ist assumption: No ablation at the edge}

The upper part of the ice which moves faster than the lower part (regarded as at a complete standstill) overrides the underlying ice in a manner similar to tractor caterpillar motion or to a rapid flow of very viscous liquids, so that each surface layer reaches the floor at the edge. 
2nd assumption: Ablation is equal to ice advancement

While the ice in the interior flows essentially parallel to the surface, the surface of the ramp formed by ablation provides a shorter direction of relief than the previously horizontal flow direction. Every flow line will be warped upwards. A flow plane loaded with bottom material constitutes a shear plane. Since the condition becomes stabilized for a longer period in certain places, a large amount of debris accumulates along the edge of the ice surface becoming a shear moraine.

\section{3rd assumption: The amount of ice removed by ablation exceeds the amount arriving}

This results in a condition similar to the one described above. When ablation begins to affect the ice behind the chain of shear moraine hills, a second set of shear planes may be formed further away from the edge of the ice. Differential motion across the older shear planes ceases gradually, and the new ones become more active.

The question of how the debris is mechanically incorporated into the ice is somewhat separate, since this paper discusses events at the edge of the ice cap. The recent paper by Weertman (196I) discusses a possible mechanism for such an incorporation: Weertman presumes the existence of melt water at the bottom of the ice sheet, which is the main reason for the material freezing into the ice. Field investigations being planned for the near future will substantiate or disprove this postulation.

\section{Conclusions}

I. The textbook concept of a "bulldozing" edge of an ice sheet does not correspond to conditions found in TUTO. Glacial geologists present numerous examples of terminal moraine buried by glacial till of subsequent glaciations without being destroyed. With the exception of some cases of outlet glaciers, the propagation of large ice sheets occurs apparently without any bulldozing.

2. It appears that the main action of an ice sheet on the ground surface is glacial plucking, abrasion, and incorporation of debris along shear planes. Terminal moraines appear to form on places where the ice sheet is temporarily at a standstill, independent of previous advance or retreat. Ample field evidence indicates that glacial plucking is temporary; an ice sheet flowing across a positive relief feature will tend to remove it. Debris removed by the flowing ice in the TUTO area constitutes material formerly subjected to subaerial erosion. Debris bands in the lower tunnel contain oxidized material characteristic of the upper layers of soils, while less oxidized subsoil material appears in the upper tunnel. The difference in appearance, which is readily perceptible and is also demonstrated by microscopic investigation, indicates that the material removal occurred over a short time span.

3. Blocking by proglacial debris, as suggested in one instance (Rausch, 1957) as the reason for the formation of shear moraines, is improbable in the TUTO area. The bottom of the glacier dips only gently to the east, and the ice is free to advance across Lake Tuto.* It is, therefore, improbable that an obstruction to ice motion produces an upward tilt of shear zones. The opposite is easier to visualize: if the bottom of the glacier becomes fully or partially immobilized, resulting in a greater difference between the speed of the upper and deeper parts of the ice, any upward curved shear zone will tend to become horizontal.

4. Shear-plane distortion (upwarping), and therefore the formation of shear moraines on the ice, may be due to the unloading effect of ablation. The interior ice of an ice sheet moves with a vertical velocity distribution similar to that of Figure 5 , in an idealized condition it would have the same rate of motion at every point at a given depth.

* Measurements in Lake Tuto conducted by Abel (in press) in $195^{8}$ and 1959, together with some results of seismic surveying, indicate that the glacier floor in the vicinity of the tunnel dips gently to the east. 


\section{Recommended Further Research}

In order that the formation of shear moraines be more thoroughly studied and understood, further research is necessary on the following problems:

I. The contact zone between the glacier bottom and ground surface should be located.

2. The nature of the interaction occurring in the zone which contains the glacierground surface interface should be studied.

3. The mechanics of the migration of inclusion bands which occurs during the formation of glacial shear moraines should be investigated.

\section{Acknowledgements}

The author wishes to express his gratitude to Dr. J. F. Nye, whose stimulating thoughts during field trips on the occasion of his last visit to Greenland helped to formulate the ideas in this paper.

Mr. John F. Abel Jr. collected numerous data on inclusions and their mechanical composition.

MS. received 27 October ${ }_{19} 6 I$

\section{R E F E R E N C E S}

Abel, J. F. In press. Under-ice mining techniques. U.S. Snow, Ice and Permafrost Research Establishment. Technical Report 72.

Bishop, B. C. 1957. Shear moraines in the Thule area, north-west Greenland. U.S. Snow, Ice and Permafrost Research Establishment. Research Report 17.

Griffiths, T. M. 1960. Glaciological investigations in the TUTO area of Greenland. U.S. Snow, Ice and Permafrost Research Establishment. Technical Report 47.

Harrison, P. W. 1957. New technique for three-dimensional fabric analysis of till and englacial debris containing particles from 3 to $40 \mathrm{~mm}$. in size. Fournal of Geology, Vol. 65, No. 1, p. 98-105.

Hilty, R. E. 1959. Measurements of ice tunnel deformation, Camp Red Rock, Greenland. U.S. Snow, Ice and Permafrost Research Establishment. Special Report 28.

Rausch, D. O. 1957 . Interim report, ice tunnel, T uto area. Denver, University of Denver Press.

Rausch, D. O. 1958. Ice tunnel, Tuto area, Greenland. U.S. Snow, Ice and Permafrost Research Establishment. Technical Report 44 .

Schytt, V. 1955. Glaciological investigations in the Thule Ramp area. U.S. Snow, Ice and Permafrost Research Establishment. Report 28 .

Weertman, J. 1961. Mechanism for the formation of inner moraines found near the edge of cold ice caps and ice sheets. Fournal of Glaciology, Vol. 3 , No. 30, p. 965-78. 